\title{
Prediction of preeclampsia and induced delivery at $<34$ weeks gestation by sFLT- 1 and PIGF in patients with abnormal midtrimester uterine Doppler velocimetry: a prospective cohort analysis
}

Johannes Stubert ${ }^{*}$, Stefanie Ullmann ${ }^{1}$, Michael Bolz ${ }^{1}$, Thomas Külz², Max Dieterich ${ }^{1}$, Dagmar-Ulrike Richter ${ }^{1}$ and Toralf Reimer ${ }^{1}$

\begin{abstract}
Background: Women with bilateral abnormal uterine artery Doppler velocimetry (UtADV) are at increased risk for an adverse pregnancy outcome. This study aimed to determine if additional assessment of midtrimester angiogenic factors improves the predictive accuracy of Doppler results for various outcome parameters.

Methods: Women with a bilateral abnormal UtADV, which was defined as a postsystolic incision and/or an increased pulsatility index greater than the $95^{\text {th }}$ centile, and a singleton pregnancy were prospectively recruited between $19+0$ and $26+6$ weeks of gestation. Maternal serum levels of placental growth factor (PIGF) and soluble fms-like tyrosine kinase-1 (sFLT-1) were measured with a fully automated immunoassay and their ratio was calculated.

Results: Angiogenic factors could predict the development of preeclampsia (PE), as well as induced delivery at $<34$ weeks of gestation, but failed to predict the development of normotensive intrauterine growth restriction. Twelve (24.0\%) of the 50 recruited women developed PE. Nine of these patients had early-onset disease $(<34+$ 0 weeks). Six (12.0\%) patients were delivered at $<34+0$ weeks. The most useful test results in the prediction of PE and induced delivery at $<34+0$ weeks were observed using the sFLT-1/PIGF $>95^{\text {th }}$ centile ratio with a sensitivity, specificity, positive predictive value, and negative predictive value (NPV) of $66.7 \%, 89.5 \%, 66.7 \%$, and $89.5 \%$ for PE, and $85.7 \%, 86.1 \%, 50.1 \%$, and $97.4 \%$ for induced delivery, respectively. Positive and negative likelihood ratios were 6.33 (95\% Cl 2.31-17.38) and 0.37 (95\% Cl 0.17-0.84) for PE, and $6.14(95 \% \mathrm{Cl} 2.76-13.69)$ and 0.17 (0.03-1.02) for induced delivery, respectively. Corresponding odds ratios were 17.0 (95\% Cl 3.5-83.0) and $37.0(95 \% \mathrm{Cl} 3.8-363.9)$, respectively.
\end{abstract}

Conclusions: Measurement of angiogenic factors improves the specificity of an abnormal UtADV for prediction of PE. Compared with prediction of PE an abnormal SFLT-1/PIGF ratio revealed higher sensitivity for prediction of induced delivery at $<34+0$ weeks. The NPV of $97 \%$ will help to reassure most patients with an abnormal UtADV and a normal sFLT-1/PIGF ratio.

Keywords: Angiogenic factors, PIGF, sFLT-1, Preeclampsia, Sensitivity, Specificity

\footnotetext{
*Correspondence: johannes.stubert@uni-rostock.de

'Department of Obstetrics and Gynecology, University of Rostock, Suedring

81, 18059 Rostock, Germany

Full list of author information is available at the end of the article
} 


\section{Background}

The estimated incidence of preeclampsia (PE) is between $0.4-2.8 \%$ of all pregnancies in Europe [1,2]. Only 15-20\% of PE is present a severe clinical course [3]. The majority of severe PE develops early in pregnancy ( $<34$ weeks of gestation) and is frequently associated with a serious maternal and foetal outcome [4-6].

Angiogenic factors have a large effect on development of preeclamptic syndrome [7]. The extent of the antiangiogenic shift, characterized by an increase in antiangiogenic soluble fms-like tyrosine kinase (sFlt)-1 and a decrease in angiogenic placental growth factor (PlGF), correlates with disease severity and precedes the clinical manifestation for several weeks [8-11]. Therefore, analysis of maternal sFLT-1 and PlGF can improve the diagnostic accuracy for detection of $\mathrm{PE}$ and allows an estimation of the clinical disease severity [12]. Moreover, removal of sFLT-1 from the maternal circulation by apheresis improves the severity of the disease and consequently prolongs the duration of pregnancy [13].

Although definitive treatment of PE is possible by delivery of the placenta alone, early prediction of high-risk patients may enhance the patient's care before disease manifestation and could help to reduce mortality and morbidity of the mother and her foetus. A widely used noninvasive approach for identifying high-risk patients comprises the performance of midtrimester Doppler ultrasound measurements of the uterine arteries. An abnormal uterine artery Doppler velocimetry (UtADV) during the second trimester has shown detection rates for PE between $40 \%$ and $80 \%$ in patients at low risk [14]. Generally, sensitivity is better for the detection of severe and/or early-onset PE compared to mild and late onset cases, but positive predictive accuracy is quite low, and the majority of patients with an abnormal UtADV will not develop PE [15]. However, additional analysis of angiogenic markers may improve the test accuracy for detecting PE. Our prospective study aimed to evaluate sFLT-1 and PlGF as predictive markers for PE in a high-risk collective as identified by an abnormal UtADV in the second trimester.

\section{Methods}

\section{Selection and inclusion criteria of patients}

Patients with a bilateral abnormal UtADV between $19+0$ and $26+6$ weeks of gestation were included in this prospective cohort study. The clinical trial was conducted at the Department for Obstetrics and Gynaecology of the University of Rostock, Germany in cooperation with the outpatient centre of prenatal diagnosis "Praxiszentrum Frauenheilkunde" in Rostock between February 2011 and July 2013. The study was approved by the institutional review board of the University of Rostock (IRB No. A2010100) and written informed consent was obtained from all participating patients. An abnormal UtADV was assumed if a bilaterally increased pulsatility index (PI) greater than the $95^{\text {th }}$ centile and/or a distinct postsystolic incision ("notch") were detected [16]. All measurements were performed by two experienced observers following the recommendations for Doppler ultrasonography measurements in obstetrics [17]. For ultrasound examinations, the Voluson 730, Voluson G8 (both GE Medical Systems, Milwaukee, WI, USA), and HDI5000 SonoCT (Philips Medical Systems, Bothell, WA, USA) were used. Gestational age was calculated from the first day of the last menstrual period and was corrected by ultrasound if measurements of the crown-rump-length during the first trimester revealed a difference of more than 7 days. PE was defined as being present when blood pressure was $\geq 140 / 90 \mathrm{mmHg}$ (taken twice, $6 \mathrm{~h}$ apart) combined with proteinuria $\geq 300 \mathrm{mg}$ in a $24-\mathrm{h}$ collection [18]. Inclusion of patients with chronic hypertension (blood pressure level $\geq 140 / 90 \mathrm{mmHg}$ prior to 20 weeks of gestation) was possible. In these cases, new onset of proteinuria $\geq 300 \mathrm{mg}$ per day was regarded as superimposed PE. According to the clinical manifestation, PE was assigned to early onset ( $<34$ weeks of gestation) or late onset ( $\geq 34$ weeks) [19]. Haemolysis, elevated liver enzymes, and low platelets (HELLP) syndrome was defined as being present, when the platelet count was less than $100 \times 10^{9} / \mathrm{L}$ (normal range: $150-450 \times 10^{9} / \mathrm{L}$ ), haptoglobin serum levels were below $0.3 \mathrm{~g} / \mathrm{L}$ (normal range: $0.3-2.0 \mathrm{~g} / \mathrm{L}$ ), and aspartate transaminase (AST) levels were $>70 \mathrm{U} / \mathrm{L}$ (normal range: $3-34 \mathrm{U} / \mathrm{L}$ ). Only singleton pregnancies were included. Exclusion criteria were maternal age $<18$ years, on-going therapy with glucocorticoids or non-steroidal analgesics (with exception of aspirin $100 \mathrm{mg}$ daily), and the presence of anti-phospholipid syndrome.

Small for gestational age (SGA) was defined as a birth weight less than the $10^{\text {th }}$ centile for gestational age according to Voigt et al. [20]. Intrauterine growth restriction (IUGR) was assumed when a SGA birth weight was combined with at least one of the following criteria: (1) oligohydramnios with an amniotic fluid index $<5 \mathrm{~cm}$, (2) persistent bilateral abnormal UtADV, (3) a pathological cardiogram, (4) a decrease in foetal growth by ultrasound biometry ("crossing centiles"), and (5) increased PI of the umbilical artery greater than the $95^{\text {th }}$ centile. Because clinicians were not aware of biomarker results, an effect of decision making for the obstetric approach was excluded.

\section{Sample collection and immunoassays}

From each study patient, $2 \times 7.5 \mathrm{~mL}$ of venous blood was taken at the time of Doppler measurement using a serum collection tube (Sarstedt, Nümbrecht, Germany). The blood clot was immediately separated by centrifugation at $2000 \times \mathrm{g}$ for $10 \mathrm{~min}$ at $15^{\circ} \mathrm{C}$ and serum was stored 
in $1-\mathrm{mL}$ aliquots at $-80^{\circ} \mathrm{C}$ until further investigations were performed. Serum concentrations of PIGF and sFLT-1 were measured with the fully automated Elecsys ${ }^{\oplus}$ sandwich immunoassays (Roche Diagnostics, Penzberg, Germany) based on streptavidin-biotin technology. The assays were performed using the Roche immunoanalyser Elecsys ${ }^{\oplus}$ 2010/ cobas e 411 according to the recommendations of the manufacturer. Within and between run coefficients of variation were below $4 \%$ for sFLT-1 $>60 \mathrm{pg} / \mathrm{mL}$ and PlGF $>20 \mathrm{pg} / \mathrm{mL}$. Functional sensitivity was $<5 \mathrm{pg} / \mathrm{mL}$ $[21,22]$. Results were classified using gestational agedependent centile curves that were provided by the manufacturer and based on data from Verlohren and colleagues [10]. Results were regarded as pathological if sFLT-1 or the ratio of sFLT-1/PIGF was greater than the $95^{\text {th }}$ centile and/or PIGF was less than the $5^{\text {th }}$ centile.

\section{Statistical analysis}

All data were stored and analysed using the IBM SPSS statistical package 19.0 (SPSS Inc. Chicago, IL, USA) and Excel 2010 (Microsoft Corporation, Redmond, WA, USA). Descriptive statistics were computed for continuous and categorical variables. The statistics included mean, median, standard deviation (SD), minimum, maximum, and number of available observations of continuous variables. Values of continuous variables are presented as mean $\pm \mathrm{SD}$. For categorical variables, frequencies and relative frequencies are shown. Testing for differences of continuous variables between the groups was accomplished by the ANOVA or the Kruskal-Wallis test, as appropriate. Test selection was based on evaluation of the variables for normal distribution by using the Kolmogorov-Smirnov test. Comparison between the groups for categorical variables was performed using the chi-square test. All $\mathrm{P}$ values resulted from two-sided statistical tests and values of $\mathrm{P}<0.05$ were considered as statistically significant. Criteria of diagnostic validity for sFLT-1 and PIGF alone, as well as the sFLT-1/PlGF ratio, were computed and presented as sensitivity, specificity, positive predictive value (PPV), negative predictive value (NPV), positive likelihood ratio, and negative likelihood ratio. Furthermore, receiver operating characteristic (ROC) curves were calculated and the areas under the curves (AUCs) were reported. The most useful cut-off values were calculated by identification of the highest score for sensitivity and specificity. For the sFLT-1/PIGF ratio $>95^{\text {th }}$ centile, odds ratios (OR) were computed for various outcome parameters. The logistic regression model was used to assess the independence of specific outcome parameters. Variables yielding $\mathrm{P}$ values $\leq 0.05$ in univariate analysis were entered in the multivariate model and adjusted for maternal body mass index, parity, onset of $\mathrm{PE}$, existence of chronic hypertension, week of gestation at the moment of blood sampling, and use of acetylsalicylic acid. We performed post hoc analysis for estimation of the statistical power of our study collective by logistic regression analysis using $G^{*}$ Power 3.1.9.2 [23]. One-tailed power analysis for prediction of PE by the sFLT-1/PIGF ratio with an $\alpha$ error of 0.05 revealed a statistical power of $95.5 \%$ for our sample size.

\section{Results}

\section{Patients' characteristics}

The patients' characteristics are shown in Table 1 with the following prevalence of subgroups: PE was found in $24.0 \%(12 / 50)$ of patients, IUGR in $12.0 \%(6 / 50)$, gestational hypertension in $32.0 \%(16 / 50)$, and others in $32.0 \%(16 / 50)$. Subgroup analysis did not show any differences between maternal characteristics, such as age, gravidity, parity, and body mass index. In contrast, significant intergroup differences were found regarding foetal/neonatal parameters. More than $40 \%$ of all preeclamptic newborns showed a SGA birth weight. Newborns in the PE subgroup also presented with the lowest mean gestational age. Consequently, the mean birth weight in cases of PE was significantly lower compared with that in the other subgroups, including newborns with normotensive IUGR. Delivery at $<34+0$ weeks occurred in $14.0 \%(7 / 50)$ of all patients. Five of them (71.4\%) had PE and two had severe hypertension without proteinuria. All of these patients had an induced delivery because of a severe clinical course indicated by the physicians on duty. One patient with chronic hypertension and concomitant diabetes mellitus type II had an intrauterine foetal death at 26 weeks of gestation. Induction of lung maturation with betamethasone was not performed in three newborns with induced delivery at $<34+0$ weeks, including the patient with intrauterine foetal death. Doppler measurements were repeated in all of the patients after 4 weeks. An abnormal UtADV normalized in $32.0 \%$ $(16 / 50)$ of all cases. There were significant differences between subgroups $(\mathrm{P}=0.047)$ with normalization of an abnormal uterine Doppler in $0.0 \%$ of PE (0/12), 33.3\% of IUGR (2/6), 31.3\% of gestational hypertension (5/16), and $56.3 \%$ in the remaining patients $(9 / 16)$.

\section{Prediction of PE by UtADV, PIGF, sFLT-1, and the sFLT-1/ PIGF ratio}

The prevalence of PE in our high-risk study collective was $24.0 \%(12 / 50)$, with $75.0 \%$ (9/12) early-onset and $25.0 \%(3 / 12)$ late-onset diseases. PE was also present with chronic hypertension in four cases (all early onset). One patient developed concomitant HELLP syndrome. For prediction of PE, bilateral UtADV showed a PPV of only $24.0 \%$ with a false-positive rate (FPR) of $76.0 \%$. Performance of ROC analysis using the mean PI of the uterine arteries showed an AUC of 0.630. At the optimal cut-off with a mean uterine $\mathrm{PI} \geq 1.86$, the specificity increased to 
Table 1 Maternal and foetal characteristics of the study population

\begin{tabular}{|c|c|c|c|c|c|c|}
\hline Characteristic & All patients $(n=50)$ & $P E(n=12)$ & IUGR $(n=6)^{\#}$ & $\mathrm{GH}(n=16)$ & Others $(n=16)$ & P-value \\
\hline \multicolumn{7}{|l|}{ Age, y } \\
\hline Mean \pm SD & $29.7 \pm 4.9$ & $29.8 \pm 3.9$ & $33.3 \pm 4.8$ & $28.3 \pm 3.6$ & $29.6 \pm 6.3$ & $0.206^{*}$ \\
\hline Minimum - maximum & $19-40$ & $24-38$ & $28-40$ & $22-34$ & $19-39$ & \\
\hline Gravidity & & & & & & $0.613^{* *}$ \\
\hline Median & 1 & 1 & 2 & 1 & 2 & \\
\hline Minimum - maximum & $1-9$ & $1-9$ & $1-8$ & $1-5$ & $1-5$ & \\
\hline Parity & & & & & & $0.612^{* *}$ \\
\hline Median & 0 & 0 & 0 & 0 & 0 & \\
\hline Minimum - maximum & $0-5$ & $0-4$ & $0-5$ & $0-2$ & $0-1$ & \\
\hline Body mass index (pregravid), $\mathrm{kg} / \mathrm{m}^{2}$ & & & & & & $0.132^{*}$ \\
\hline Mean \pm SD & $27.1 \pm 8.2$ & $30.6 \pm 8.0$ & $21.7 \pm 3.2$ & $28.1 \pm 9.1$ & $25.6 \pm 6.3$ & \\
\hline Minimum - maximum & $14.5-47.0$ & $19.8-45.0$ & $18.7-27.3$ & $14.5-45.7$ & $18.8-47.0$ & \\
\hline Chronic hypertension, n (\%) & $8(16.0 \%)$ & $4(33.3 \%)$ & $0(0.0 \%)$ & $4(25.0 \%)$ & $0(0.0 \%)$ & $0.049^{* * *}$ \\
\hline Thrombophilia, n (\%) & $5(10.0 \%)$ & $0(0.0 \%)$ & $0(0.0 \%)$ & $3(18.8 \%)$ & $2(12.5 \%)$ & $0.755^{* * *}$ \\
\hline Nicotine abuse, $n$ (\%) & $14(28.0 \%)$ & $5(41.7 \%)$ & $1(16.7 \%)$ & $6(37.5 \%)$ & $2(12.5 \%)$ & $0.238^{* * *}$ \\
\hline Highest systolic blood pressure, $\mathrm{mmHg}$ & & & & & & $<0.001^{*}$ \\
\hline Mean \pm SD & $143.2 \pm 23.1$ & $165.8 \pm 21.2$ & $128.7 \pm 5.4$ & $149.4 \pm 20.0$ & $124.7 \pm 9.9$ & \\
\hline Minimum - maximum & $110-200$ & $140-200$ & $120-135$ & $130-200$ & $110-140$ & \\
\hline Highest diastolic blood pressure, $\mathrm{mmHg}$ & & & & & & $<0.001^{*}$ \\
\hline Mean \pm SD & $90.4 \pm 17.6$ & $110.5 \pm 13.4$ & $79.7 \pm 6.2$ & $91.8 \pm 15.9$ & $77.3 \pm 7.1$ & \\
\hline Minimum - maximum & $60-130$ & $90-130$ & $70-86$ & $60-124$ & $60-90$ & \\
\hline \multicolumn{7}{|l|}{ Proteinuria, mg/d } \\
\hline Mean \pm SD & $1180 \pm 2524$ & $2613 \pm 3394$ & n.a. & $157 \pm 196$ & n.a. & \\
\hline Minimum - maximum & $0-9986$ & $109-9986$ & n.a. & $0-283$ & n.a. & \\
\hline Placenta weight, g & & & & & & $0.129^{*}$ \\
\hline Mean \pm SD & $324 \pm 98$ & $300 \pm 86$ & $322 \pm 29$ & $286 \pm 145$ & $443 \pm 71$ & \\
\hline Minimum - maximum & $124-510$ & $182-461$ & $283-364$ & $124-476$ & $369-510$ & \\
\hline Amnion fluid index (AFI), $n(\%)$ & & & & & & $0.839^{* * *}$ \\
\hline Oligohydramnion (AFI $\leq 8)$ & $13(26.0 \%)$ & $3(25.0 \%)$ & $2(33.3 \%)$ & $4(25.0 \%)$ & $4(25.0 \%)$ & \\
\hline Polyhydramnion (AFI > 18) & $7(14.0 \%)$ & $3(25.0 \%)$ & $1(16.7 \%)$ & $1(6.3 \%)$ & $2(12.5 \%)$ & \\
\hline Birth weight, $g$ & & & & & & $<0.001^{*}$ \\
\hline Mean \pm SD & $2588 \pm 809$ & $1859 \pm 658$ & $2270 \pm 303$ & $2588 \pm 750$ & $3175 \pm 626$ & \\
\hline Minimum - maximum & $620-3940$ & $890-2980$ & $1750-2620$ & $620-3610$ & $1860-3940$ & \\
\hline \multicolumn{7}{|l|}{ Percentile of birth weight, $n$ (\%) } \\
\hline SGA $\left(<10^{\text {th }}\right.$ centile $)$ & $16(32.0 \%)$ & $5(41.7 \%)$ & $6(100.0 \%)$ & $6(37.5 \%)$ & $0(0.0 \%)$ & \\
\hline LGA $\left(>90^{\text {th }}\right.$ centile) & $0(0.0 \%)$ & $0(0.0 \%)$ & $0(0.0 \%)$ & $0(0.0 \%)$ & $0(0.0 \%)$ & \\
\hline 5'-APGAR-Score & & & & & & $0.398^{* *}$ \\
\hline Median & 10 & 9 & 10 & 10 & 10 & \\
\hline Minimum - maximum & $8-10$ & $8-10$ & $9-10$ & $8-10$ & $9-10$ & \\
\hline Induction of lung maturation, $\mathrm{n}(\%)$ & $13(26.0 \%)$ & $4(33.3 \%)$ & $6(100.0 \%)$ & $2(12.5 \%)$ & $1(6.3 \%)$ & $0.019^{* * *}$ \\
\hline
\end{tabular}


Table 1 Maternal and foetal characteristics of the study population (Continued)

\begin{tabular}{|c|c|c|c|c|c|c|}
\hline Newborns $<34+0$ weeks, $n(\%)$ & $7(14.0 \%)$ & $5(41.7 \%)$ & $0(0.0 \%)$ & $2(12.5 \%)$ & $0(0.0 \%)$ & $0.008^{* * *}$ \\
\hline Gestational age at delivery, weeks + days & & & & & & $0.009^{* *}$ \\
\hline Mean $(w+d) \pm S D(d)$ & $37+2 \pm 24$ & $34+4 \pm 26$ & $37+5 \pm 5$ & $37+4 \pm 25$ & $38+6 \pm 17$ & \\
\hline Minimum - maximum & $26+4-42+0$ & $27+4-40+3$ & $36+5-39+0$ & $26+2-41+0$ & $34+1-42+0$ & \\
\hline
\end{tabular}

\# normotensive IUGR only.

* = ANOVA.

** $=$ Kruskal-Wallis test.

$* * *=$ Chi-Square test

n.a. = not available, $\mathrm{PE}=$ Preeclampsia, $\mathrm{GH}=$ Gestational hypertension, IUGR = Intrauterine growth restriction, SGA = Small for gestational age, LGA $=$ Large for gestational age.

$72.2 \%$, with a PPV of $38.2 \%$. However, the false negative rate also increased to $45.5 \%$, resulting in a predictive accuracy of only $70.0 \%$. In contrast, serum levels of PIGF and sFLT-1, as well as the sFLT-1/PlGF ratio, clearly improved discrimination between patients with and without PE (Figure 1, Table 2). If values were greater than the $95^{\text {th }}$ centile of gestation, the sFLT-1/ PIGF ratio showed most useful test characteristics for $\mathrm{PE}$, with a sensitivity of $66.7 \%$ and an FPR of only $10.5 \%$ (Table 3). The corresponding PPV was $66.7 \%$, with an NPV of $89.5 \%$ and a predictive accuracy of the ratio of $84.0 \%$. An elevated sFLT-1/PlGF ratio greater than the $95^{\text {th }}$ centile was associated with an increased risk for development of PE (OR 17.0; 95\% confidence interval $[\mathrm{CI}]$ 3.5-83.0, $\mathrm{P}<0.001$ ) (Table 3). Results remained significant after weighting of parameters in multiple regression analysis with an adjusted OR for PE (adjusted OR 14.1; 95\% CI 1.1-182.6, P = 0.043).

The sensitivity increased to $75.0 \%$ if only early-onset PE was included, but FPR also increased to $14.3 \%$. We found four false-positive cases, where one patient showed a normotensive IUGR and two had hypertension without proteinuria (one with concomitant IUGR and one with intrauterine foetal death at 26 weeks of gestation). Two out of the four false-negative patients developed earlyonset PE (one patient with concomitant HELLP syndrome at $<34$ weeks of gestation) and two developed late-onset $\mathrm{PE}$ (with only a mild clinical course in one patient). The fourth patient with false-negative serum markers developed late-onset $\mathrm{PE}$, but fulfilled the criteria of severity with hypertension $>160 / 110 \mathrm{mmHg}$. ROC analysis showed an AUC of 0.721 for the sFLT-1/PIGF ratio, with the best predictive cut-off of 13.0, resulting in a sensitivity of $66.7 \%$ with an FPR of 13.2\% (Figure 2, Table 4). If a fixed FPR of $10 \%$ was assumed, the cut-off level of the ratio changed to 22.4 , with a sensitivity of only $41.7 \%$.

\section{Prediction of hypertension without proteinuria, IUGR, and} induced delivery at $<34$ weeks of gestation

Results were further analysed in respect to development of hypertension without proteinuria and IUGR. As shown in Table 2, serum levels of PIGF were significantly lower in cases of IUGR compared to uncomplicated controls ( $\mathrm{P}=$ $0.033)$, but failed significance if used as predictive parameter throughout the whole study population (Table 3). However, we found significant differences of the angiogenic markers if results were analysed in relation to gestational age at delivery (Figure 3). Measurements of sFLT-1 and PlGF were useful predictive markers for delivery at $<34+$ 0 weeks of gestation. If ROC analysis was performed, the AUC for the sFLT-1/PlGF ratio was 0.877 , with a best cutoff of 13.0 (Figure 2). This cut-off resulted in a sensitivity of $85.7 \%$ with an FPR of $16.3 \%$. If gestational agedependent threshold levels greater than the $95^{\text {th }}$ centile were used, the FPR improved to $13.9 \%$ with the same sensitivity. The PPV and NPV were $50.1 \%$ and $97.4 \%$,

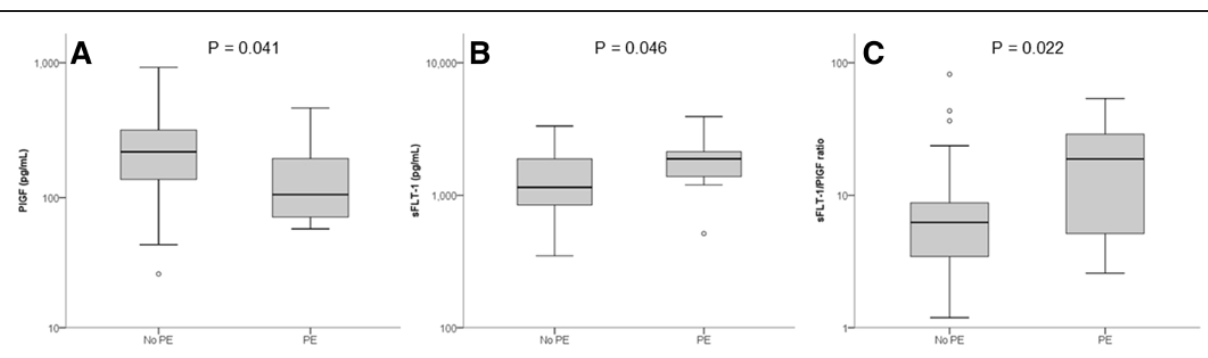

Figure 1 Prediction of PE. Boxplot analysis of maternal serum PIGF (A) and SFLT-1 (B) levels and their ratio (C). Patients with development of preeclampsia ( $P E, n=12)$ were compared with all patients without $P E(n=38)$. Boxes show the median (black line), and $25^{\text {th }}$, and $75^{\text {th }}$ percentiles (top and bottom lines of the box). The lines outside the box represent minimum and maximum values. Circles are outliers $(>1.5 \times$ from the interquartile range). $P$ values were computed by Mann-Whitney statistical tests. 
Table 2 Maternal serum PIGF and sFLT-1 levels and their ratio

\begin{tabular}{|c|c|c|c|c|c|c|c|c|c|c|c|}
\hline & $\mathrm{PE}(\mathrm{n}=12)$ & No PE $(n=38)$ & $P_{\text {-value }}{ }^{a}$ & $\begin{array}{l}\text { Others }(n=16) \\
\text { (Uncomplicated) }\end{array}$ & $\mathrm{GH}(n=16)$ & P-value ${ }^{b}$ & $\begin{array}{l}\text { Normotensive } \\
\text { IUGR }(n=6)\end{array}$ & P-value ${ }^{c}$ & $\begin{array}{l}\text { Delivery < } 34 \\
\text { weeks }(n=7)\end{array}$ & $\begin{array}{l}\text { Delivery } \geq 34 \\
\text { weeks }(n=44)\end{array}$ & P-value ${ }^{d}$ \\
\hline PIGF (pg/mL) & $105.6(70.7-248.7)$ & $218.5(131.2-322.5)$ & 0.041 & 274.6 (157.9-413.6) & $\begin{array}{l}198.7 \\
(91.5-305.3)\end{array}$ & 0.142 & $\begin{array}{l}165.9 \\
(72.1-220.7)\end{array}$ & 0.033 & $75.1(64.6-131.7)$ & $\begin{array}{l}221.7 \\
(117.4-336.4)\end{array}$ & 0.003 \\
\hline sFLT-1 (pg/mL) & $1879.0(1379.5-2168.3)$ & $1144.0(842.2-1882.8)$ & 0.046 & $\begin{array}{l}1458.0 \\
(1018.8-1896.3)\end{array}$ & $\begin{array}{l}1032.6 \\
(826.8-1649.8)\end{array}$ & 0.258 & $\begin{array}{l}1324.4 \\
(673.1-2012.0)\end{array}$ & 0.768 & $\begin{array}{l}2158.0 \\
(1858.0-3463.0)\end{array}$ & $\begin{array}{l}1298.0 \\
(846.1-1876.0)\end{array}$ & 0.008 \\
\hline sFLT-1/PIGF ratio & $18.8(4.8-29.1)$ & $6.2(3.4-8.8)$ & 0.022 & $5.9(2.9-8.6)$ & $5.9(3.6-9.1)$ & 0.366 & $8.6(4.0-19.6)$ & 0.161 & $29.4(14.1-53.9)$ & $6.0(3.4-9.0)$ & 0.001 \\
\hline
\end{tabular}

Data are given as median (interquartile range).

a Mann-Whitney statistical test comparing PE vs No PE.

${ }^{\mathrm{b}}$ Mann-Whitney statistical test comparing GH vs Others.

cMann-Whitney statistical test comparing IUGR vs Others.

d Mann-Whitney statistical test comparing delivery $<34$ weeks vs delivery $\geq 34$ weeks.

$\mathrm{PE}=$ Preeclampsia, $\mathrm{GH}=$ Gestational hypertension, IUGR = Intrauterine growth restriction. 
Table 3 Diagnostic indices of maternal PIGF, sFLT-1, and their ratio for identifying patients who will develop preeclampsia, hypertension without proteinuria, normotensive IUGR, and induced delivery at $<34$ weeks of gestation

\begin{tabular}{|c|c|c|c|c|c|c|c|c|c|}
\hline & & $\begin{array}{l}\text { Chi-Square } \\
\text { P-value }\end{array}$ & Sensitivity & Specificity & PPV & NPV & $\mathrm{LR}+(95 \% \mathrm{Cl})$ & LR- $(95 \% \mathrm{Cl})$ & OR $(95 \% \mathrm{Cl})$ \\
\hline \multirow[t]{3}{*}{$\operatorname{PE}(n=12)$} & PIGF & 0.027 & $58.3 \%$ & $78.9 \%$ & $46.7 \%$ & $85.7 \%$ & $2.77(1.27-6.04)$ & $0.53(0.27-1.05)$ & $5.25(1.31-21.03)$ \\
\hline & sFLT-1 & 0.240 & $16.7 \%$ & $94.7 \%$ & $50.0 \%$ & $78.3 \%$ & $3.17(0.50-20.13)$ & $0.88(0.68-1.15)$ & $3.60(0.45-28.86)$ \\
\hline & sFLT-1/PIGF ratio & $<0.001$ & $66.7 \%$ & $89.5 \%$ & $66.7 \%$ & $89.5 \%$ & $6.33(2.31-17.38)$ & $0.37(0.17-0.84)$ & $17.0(3.50-83.02)$ \\
\hline \multirow{3}{*}{$\begin{array}{l}\text { Gestational } \\
\text { hypertension } \\
(n=16)\end{array}$} & PIGF & 0.514 & $37.5 \%$ & $73.5 \%$ & $40.0 \%$ & $71.4 \%$ & $1.42(0.61-3.30)$ & $0.85(0.55-1.31)$ & $1.67(0.47-5.92)$ \\
\hline & sFLT-1 & 1.000 & $6.3 \%$ & $91.2 \%$ & $25.0 \%$ & $67.4 \%$ & $0.71(0.08-6.29)$ & $1.03(0.87-1.21)$ & $0.69(0.067-7.19)$ \\
\hline & sFLT-1/PIGF ratio & 0.292 & $12.5 \%$ & $70.6 \%$ & $16.7 \%$ & $63.2 \%$ & $0.43(0.11-1.72)$ & $1.24(0.93-1.65)$ & $0.34(0.07-1.79)$ \\
\hline \multirow[t]{3}{*}{ IUGR $(n=6)$} & PIGF & 0.654 & $16.7 \%$ & $68.2 \%$ & $6.7 \%$ & $85.7 \%$ & $0.52(0.08-3.30)$ & $1.22(0.81-1.84)$ & $0.43(0.05-4.02)$ \\
\hline & sFLT-1 & 1.000 & $0.0 \%$ & $90.9 \%$ & $0.0 \%$ & $87.0 \%$ & 0.00 & $1.10(1.00-1.21)$ & 0.00 \\
\hline & sFLT-1/PIGF ratio & 1.000 & $16.7 \%$ & $75.0 \%$ & $8.3 \%$ & $86.8 \%$ & $0.67(0.10-4.29)$ & $1.11(0.75-1.65)$ & $0.60(0.06-5.71)$ \\
\hline \multirow{3}{*}{$\begin{array}{l}\text { Induced delivery } \\
<34 \text { weeks }(n=7)\end{array}$} & PIGF & 0.176 & $57.1 \%$ & $74.4 \%$ & $26.7 \%$ & $91.4 \%$ & $2.23(0.98-5.07)$ & $0.58(0.34-1.38)$ & $3.88(0.75-20.12)$ \\
\hline & sFLT-1 & 0.089 & $28.6 \%$ & $95.4 \%$ & $50.3 \%$ & $89.1 \%$ & $6.14(1.03-36.79)$ & $0.75(0.47-1.20)$ & $8.20(0.94-71.73)$ \\
\hline & sFLT-1/PIGF ratio & $<0.001$ & $85.7 \%$ & $86.1 \%$ & $50.1 \%$ & $97.4 \%$ & $6.14(2.76-13.69)$ & $0.17(0.03-1.02)$ & $37.00(3.76-363.91)$ \\
\hline \multirow{3}{*}{$\begin{array}{l}\text { Early-onset } \\
P E(n=9)\end{array}$} & $\mathrm{PIGF}$ & 0.220 & $50.0 \%$ & $73.8 \%$ & $26.7 \%$ & $88.6 \%$ & $1.91(0.81-4.51)$ & $0.68(0.33-1.39)$ & $2.82(0.60-13.24)$ \\
\hline & sFLT-1 & 0.115 & $25.0 \%$ & $95.2 \%$ & $50.0 \%$ & $87.0 \%$ & $5.25(0.86-32.02)$ & $0.79(0.53-1.18)$ & $6.67(0.79-56.64)$ \\
\hline & sFLT-1/PIGF ratio & 0.001 & $75.0 \%$ & $85.7 \%$ & $50.0 \%$ & $94.7 \%$ & $5.25(2.26-12.18)$ & $0.29(0.09-0.98)$ & $18.00(2.92-110.96)$ \\
\hline \multirow{3}{*}{$\begin{array}{l}\text { Late-onset } \\
\text { PE }(n=3)\end{array}$} & PIGF & 0.075 & $75.0 \%$ & $73.9 \%$ & $20.0 \%$ & $97.1 \%$ & $2.88(1.36-6.06)$ & $0.34(0.06-1.86)$ & $8.50(0.81-89.75)$ \\
\hline & sFLT-1 & 1.000 & $0.0 \%$ & $91.3 \%$ & $0.0 \%$ & $91.3 \%$ & 0.00 & $1.10(1.00-1.20)$ & 0.00 \\
\hline & sFLT-1/PIGF ratio & 0.240 & $50.0 \%$ & $78.3 \%$ & $16.7 \%$ & $94.7 \%$ & $2.30(0.75-7.07)$ & $0.64(0.24-1.72)$ & $3.60(0.46-28.86)$ \\
\hline
\end{tabular}

Cut-off levels were defined as $<5^{\text {th }}$ centile for PIGF and $>95^{\text {th }}$ centile for sFLT-1 and the sFLT-1/PIGF ratio according to gestational specific reference values. $\mathrm{PE}=$ Preeclampsia, $\mathrm{GH}=$ Gestational hypertension, IUGR = Intrauterine growth restriction, PPV = Positive predictive value, NPV = Negative predictive value, $\mathrm{OR}=$ Odds ratio, $\mathrm{LR}+/-=$ positive/negative Likelihood ratio.
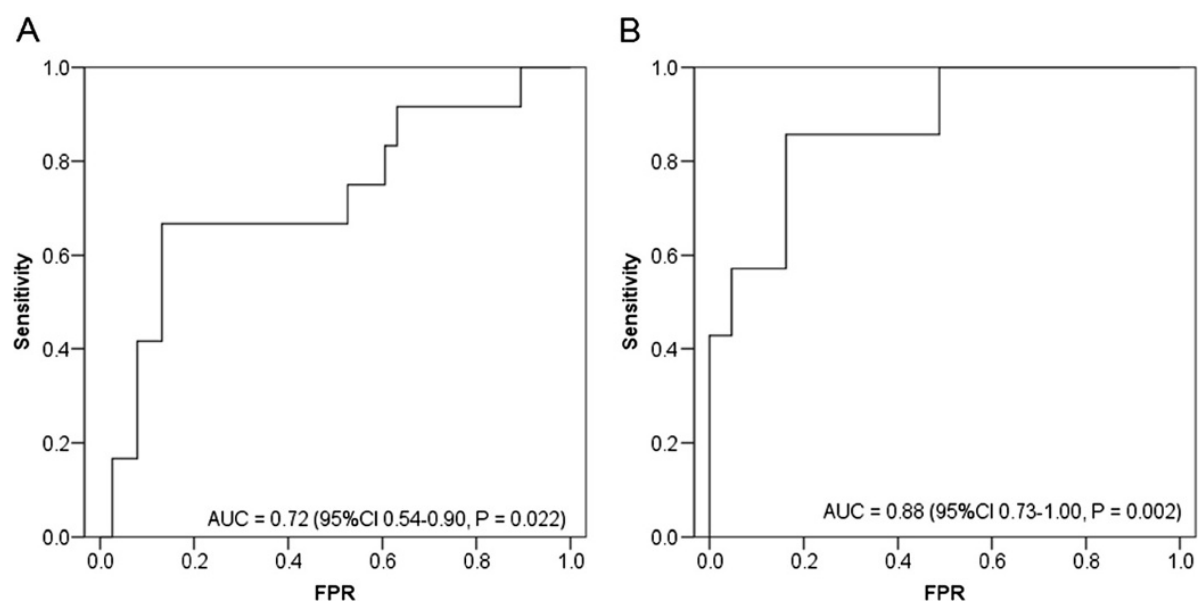

Figure 2 ROC curves for prediction of PE (A) and induced delivery at $<34$ weeks of gestation (B) by using the sFLT-1/PIGF ratio. 
Table 4 Results of receiver operating characteristic curve analysis with AUC values and cut-off levels of maternal serum PIGF $(\mathrm{pg} / \mathrm{mL})$ and sFLT-1 $(\mathrm{pg} / \mathrm{mL})$ levels and their ratio, resulting in optimal sensitivity and specificity

\begin{tabular}{|c|c|c|c|c|c|c|c|}
\hline & & AUC & Cut-off & Sensitivity & Specificity & PPV & NPV \\
\hline \multirow[t]{3}{*}{$P E(n=12)$} & PIGF & 0.697 & 133.8 & $75.0 \%$ & $76.3 \%$ & $50.0 \%$ & $90.6 \%$ \\
\hline & sFLT-1 & 0.693 & 1171.5 & $91.7 \%$ & $52.6 \%$ & $37.9 \%$ & $95.3 \%$ \\
\hline & sFLT-1/PIGF ratio & 0.721 & 13.0 & $66.7 \%$ & $86.8 \%$ & $61.5 \%$ & $89.2 \%$ \\
\hline EO PE $(n=9)$ & sFLT-1/PIGF ratio & 0.735 & 13.0 & $75.0 \%$ & $83.3 \%$ & $51.4 \%$ & $93.4 \%$ \\
\hline \multirow[t]{3}{*}{ Gestational hypertension $(n=16)$} & PIGF & 0.494 & 117.6 & $37.5 \%$ & $70.6 \%$ & $37.5 \%$ & $70.6 \%$ \\
\hline & sFLT-1 & 0.364 & 590.5 & $100.0 \%$ & $11.8 \%$ & $34.8 \%$ & $100.0 \%$ \\
\hline & sFLT-1/PIGF ratio & 0.456 & 2.3 & $100.0 \%$ & $8.8 \%$ & $34.0 \%$ & $100.0 \%$ \\
\hline \multirow[t]{3}{*}{ IUGR $(n=6)$} & PIGF & 0.640 & 262.3 & $100.0 \%$ & $38.6 \%$ & $18.2 \%$ & $100.0 \%$ \\
\hline & sFLT-1 & 0.439 & 1751.0 & $50.0 \%$ & $63.6 \%$ & $15.8 \%$ & $90.3 \%$ \\
\hline & sFLT-1/PIGF ratio & 0.564 & 8.0 & $66.7 \%$ & $56.8 \%$ & $17.4 \%$ & $92.6 \%$ \\
\hline \multirow[t]{3}{*}{ Induced delivery $<34$ weeks $(n=7)$} & PIGF & 0.834 & 133.8 & $85.7 \%$ & $72.1 \%$ & $33.3 \%$ & $96.9 \%$ \\
\hline & sFLT-1 & 0.807 & 1850.5 & $85.7 \%$ & $74.4 \%$ & $35.3 \%$ & $97.0 \%$ \\
\hline & sFLT-1/PIGF ratio & 0.877 & 13.0 & $85.7 \%$ & $83.7 \%$ & $46.1 \%$ & $97.3 \%$ \\
\hline
\end{tabular}

$\mathrm{PE}=$ Preeclampsia, $\mathrm{EO}=$ Early-onset, IUGR = Intrauterine growth restriction, ID = Induced delivery, $\mathrm{PPV}=$ positive predictive value, NPV = negative predictive value.

respectively. The ratio of sFLT-1/PIGF showed a predictive accuracy of $86.0 \%$. An elevated sFLT-1/PIGF ratio greater than the $95^{\text {th }}$ centile was associated with an increased risk for delivery at $<34+0$ weeks (OR 37.0; 95\% CI 3.8-363.9, $\mathrm{P}<0.001$ ) (Table 3). Results remained significant after weighting of parameters in multiple regression analysis with an adjusted OR (34.6; 95\% CI 1.2-1026.2, P = 0.041).

\section{Discussion}

\section{Main findings}

Patients with an abnormal UtADV showed distinct foetal and maternal morbidity, with a high prevalence of PE, IUGR, and hypertensive disorders without proteinuria. However, only one of four patients with abnormal UtADV developed PE. Additional measurement of the sFLT-1/ PlGF ratio was able to decrease the FPR from $76.0 \%$ to $10.5 \%$. A negative test result below the $95^{\text {th }}$ gestational age-specific centile showed an NPV of $89.5 \%$. The NPV was further improved if only patients with early onset PE $(94.7 \%)$ or those who required delivery at $<34$ weeks
(97.4\%) were considered. Therefore, women with a normal sFLT-1/PIGF ratio were at low risk for development of one of these severe clinical courses. Additional measurement of sFLT-1 and PlGF would be helpful to reassure the majority of patients with an abnormal UtADV. An increased angiogenic ratio was associated with an increased risk of a severe hypertensive disorder and concomitant preterm delivery. Provident corticosteroid treatment of these women should be considered.

\section{Interpretation}

There are different approaches for prediction of PE. Doppler ultrasound of the uterine arteries during the second trimester is the best-known single predictor for $\mathrm{PE}$, with a detection rate up to $80 \%$ for early-onset disease [14,24-26]. However, the majority of patients with abnormal UtADV will never develop PE, which suggests the need to improve the predictive accuracy. Therefore, use of a well-established and widely performed test for identification of a high risk collective and its combination
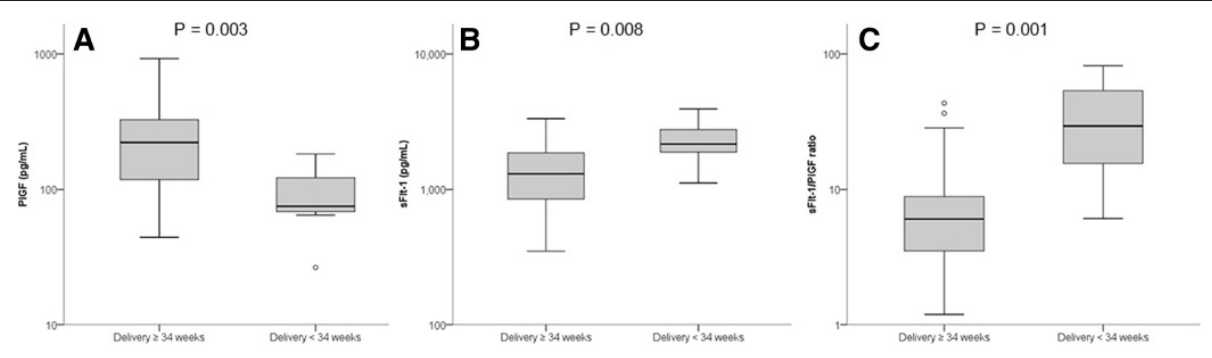

Figure 3 Prediction of preterm delivery $<34$ weeks. Boxplot analysis of maternal serum PIGF (A) and sFLT-1 (B) levels and their ratio (C). Patients with delivery at $<34$ weeks of gestation $(n=6)$ were compared with the remaining patients $(n=44)$. Boxes show the median (black line), and $25^{\text {th }}$ and $75^{\text {th }}$ percentiles (top and bottom lines of the box). The lines outside the box represent minimum and maximum values. Circles are outliers ( $>1.5 \times$ from the interquartile range). $P$ values were computed by Mann-Whitney statistical tests. 
with measurement of angiogenic factors for improvement of specificity is a practically oriented approach. The use of a fully automated diagnostic system that analyses sFLT1 and PlGF guarantees a high test quality. The Elecsys ${ }^{\oplus}$ immunoassays show high precision and reliability, and allow execution of measurements in laboratories for routine clinical diagnosis [21].

Recent studies have reported complex algorithms that allow prediction of PE by integration of miscellaneous risk factors, including analysis of angiogenic factors between 11-13 weeks of gestation [27-29]. Identification of high-risk patients during the first trimester offers the advantage of a preventive therapy with low-dose aspirin, which more than halves the risk of severe PE [30]. However, the ability of prediction or exclusion of PE during the second trimester may also be useful because it can facilitate decision making as to whether intensified patient's care or corticosteroid treatment for foetal lung maturation will be necessary. There is also increasing evidence for effective preventive treatment strategies in high-risk patients during the second trimester [31-33]. Various (nested) case-control studies have examined the differences in maternal angiogenic protein concentrations during the second trimester preceding the occurrence of $\mathrm{PE}$ [8,34-41]. The usefulness of circulating sFLT-1 and PIGF as a test to predict PE in healthy pregnant women was recently proven in a comprehensive prospective cohort study by McElrath and colleagues [11]. In a cohort of 2243 patients, the plasma levels of angiogenic factors were repeatedly measured at 10, 17, 24 , and 35 weeks of gestation. In the study sample, 139 (6.2\%) patients developed PE. At 10 weeks of gestation, the authors did not find any significant differences between plasma concentrations of PIGF or sFLT-1, or the sFLT-1/PIGF ratio in patients with PE compared with healthy controls. Differences became significant at 17 weeks for PlGF ( $\mathrm{P}=0.009)$ alone, and were highly significant for PlGF and the sFLT-1/PIGF ratio at 24 weeks $(\mathrm{P}<0.001)$. In contrast, differences for sFLT-1 became significant at 35 weeks. At 24 weeks, the highest detection rate $(62.2 \%)$ was observed for PlGF alone, with an FPR of $38.4 \%$ and a PPV of $9.5 \%$. The relative risk for development of PE was 2.46 (95\% CI 1.66--3.65) if a cut-off level of $379 \mathrm{pg} / \mathrm{mL}$ was used [11]. Similar results were shown in a further prospective study including 1622 healthy Hispanic women [25]. Maternal plasma concentrations of various angiogenic proteins were measured at 6-15 and 20-25 weeks of gestation. During pregnancy, $3.8 \%$ of patients developed PE $(n=62)$, and $0.6 \%$ had early-onset PE $(n=9)$. In midtrimester, PIGF measurements alone showed a better test performance $(\mathrm{P}<0.001)$ than sFLT-1 $(\mathrm{P}=0.5)$ or the sFLT-1/PIGF ratio $(\mathrm{P}=0.006)$. However, the detection rate for PlGF was only $51.6 \%$, with an FPR of $23.6 \%$ and a PPV of $8 \%$. A reasonable cut-off value was $215 \mathrm{pg} / \mathrm{mL}$, resulting in an OR of 3.8 (95\% CI 2.2-6.7). The detection rate for earlyonset PE was $100 \%$, and was therefore better, with an FPR of only $4.2 \%$ at a cut-off level of $126 \mathrm{pg} / \mathrm{mL}$ [25]. The authors of both studies concluded that angiogenic protein concentrations alone, measured in early or even late pregnancy, were of limited utility for prediction of PE. For prediction of PE, its low incidence and concomitant low predictive value are problematic. Therefore, identification of high-risk patients may be an alternative, more suitable approach. In a prospective cohort study of 3348 patients, Espinoza and colleagues examined the relationship between UtADV and plasma concentrations of PlGF and sFLT- 1 between 22 and 26 weeks of gestation [24]. In this study, they showed that abnormal UtADV and maternal PlGF were independent explanatory variables for the occurrence of PE. For prediction of PE, the FPR of abnormal UtADV alone was low (10.4\%). Abnormal UtADV had a better test performance than maternal PlGF for identification of a high-risk collective, with ORs for all types of PE and early-onset PE of 4.3 (95\% CI 2.82-6.66) and 24.1 (95\% CI 9.61-60.44) compared with PlGF (cut-off, $280 \mathrm{pg} / \mathrm{mL}$ ), with corresponding ORs of 2.6 (95\% CI 1.57-3.94) and 5.5 (95\% CI 1.98-15.08). The combination of both parameters increased the OR for early-onset PE to 43.8 (95\% CI 18.48-103.9). The PPV for early-onset PE was improved from $5.4 \%$ for abnormal UtADV and $1.4 \%$ for PlGF alone to $12.7 \%$ if both factors were combined with a positive likelihood ratio of 18.48 (95\% CI 13.07-26.13). This study [24] impressively showed that PIGF significantly contributed to the prediction of patients who were going to develop early-onset $\mathrm{PE}$, and thus confirmed the results of a smaller study by Stepan and colleagues [42]. The supplemental table compares the test characteristics of the sFLT-1/PIGF ratio of various studies (Additional file 1: Table S1). The prospective cohort study by Moore Simas and colleagues included only patients with at least one risk factor for PE in their medical history [43]. In this study, the determination of sFLT-1 showed a good predictive accuracy for early-onset PE, with an AUC value of 0.90 (95\% CI 0.78-1.0) between 22 and 26 weeks of gestation. The sFLT-1/PlGF ratio was even better with an AUC value of 0.97 (95\% CI 0.91-1.0). Similar results of other studies, including our own data, showed an increase in specificity if the sFLT-1/PIGF ratio instead of PIGF alone was used for prediction of early-onset PE. However, compared with a decrease in PlGF, an increase in SFLT-1 in patients with PE is a late event, with only a narrow time frame between diagnosis and clinical manifestation of PE $[8,11]$.

Although the end-point of our study was the development of PE, we additionally analysed the correlation between angiogenic factors and the occurrence of other 
adverse outcome parameters, such as IUGR and delivery at $<34$ weeks. The group of induced deliveries showed great overlap with the PE cases and could be regarded as a surrogate for a severe clinical course. Therefore, identification of these patients is of high clinical relevance. With an AUC of 0.88 , we observed a satisfactory test performance for prediction of cases with a delivery at $<34$ weeks of gestation. Although PPV was only $50.1 \%$, we found an NPV of $97.4 \%$. In patients with abnormal UtADV and a normal angiogenic ratio, the need for delivery at $<34$ weeks following hypertensive pregnancy disorders is highly unlikely. With a sensitivity of $71 \%$ and a specificity of $76 \%$, Stepan and colleagues also reported the capability of the sFLT-1/PIGF ratio for prediction of preterm delivery [42]. Additionally, in a prospective study of patients with suspected early-onset PE, the sFLT-1/ PIGF ratio showed prognostic relevance [44]. Patients with a ratio $\geq 85$ had a significantly increased risk for delivery within the next 2 weeks, with a hazard ratio of 15.2 (95\% CI 8.0-28.7).

In our study, angiogenic factors were not suitable for prediction of hypertension without proteinuria or for normotensive IUGR, although in IUGR, the levels of PlGF were significantly lower compared with inconspicuous controls. Differences reported in other studies were also only moderate, and not helpful for diagnosis or prediction of these adverse pregnancy outcome parameters $[12,41,42]$.

\section{Conclusion}

In high-risk patients, measurement of angiogenic factors shows a good predictive power for development of PE. The best results can be achieved using the ratio of sFLT-1 and PIGF, with a predictive test accuracy of $84 \%$. In patients with abnormal UtADV, a high FPR of Doppler measurement alone is improved to $10.5 \%$. An increased sFLT-1/PlGF ratio is also predictive for patients who need delivery at $<34+0$ weeks of gestation. The test performed even better for prediction of preterm delivery compared with $\mathrm{PE}$, with a sensitivity and specificity of $>80 \%$. In particular, a NPV of $97.4 \%$ can help to reassure most patients with an abnormal UtADV.

\section{Additional file}

Additional file 1: Table S1. Test indices of the midtrimester sFlt-1/PIGF ratio for prediction of preeclampsia. Comparison of relevant studies (see Discussion).

\section{Competing interests}

The authors declare that they have no competing interests.

\section{Authors' contributions}

JS conceived and designed the study, analysed and interpreted the data, and drafted the manuscript. SU acquired and analysed the patients' data, and drafted the manuscript. MB acquired patients, performed the ultrasound examination and took blood samples. TK acquired patients, performed the ultrasound examination and took blood samples. MD analysed and interpreted the data, and wrote the manuscript. DUR designed the study and acquired the lab data. TR conceived and designed the study, and wrote the manuscript. All authors have seen and approved the final version of the manuscript.

\section{Acknowledgements}

The authors would like to thank Ms Erika Greschkowitz for her assistance in laboratory processing. The study was financed by own resources of the department of Obstetrics and Gynaecology of the University of Rostock.

\section{Author details}

'Department of Obstetrics and Gynecology, University of Rostock, Suedring 81, 18059 Rostock, Germany. ${ }^{2}$ Centre of Prenatal Diagnosis "Praxiszentrum Frauenheilkunde", Suedring 81, 18059 Rostock, Germany.

Received: 2 April 2014 Accepted: 19 August 2014 Published: 28 August 2014

\section{References}

1. Dolea C, AbouZahr C: Global burden of hypertensive disorders of pregnancy in the year 2000. In Global Burden of Disease 2000. Geneva: World Health Organization; 2003. www.who.int/healthinfo/statistics/ bod_hypertensivedisordersofpregnancy.pdf.

2. Gaillard R, Arends LR, Steegers EA, Hofman A, Jaddoe WW: Second- and third-trimester placental hemodynamics and the risks of pregnancy complications: the Generation R Study. Am J Epidemiol 2013, 177:743-754.

3. Zhang WH, Alexander S, Bouvier-Colle MH, Macfarlane A: Incidence of severe pre-eclampsia, postpartum haemorrhage and sepsis as a surrogate marker for severe maternal morbidity in a European population-based study: the MOMS-B survey. BJOG 2005, 112:89-96.

4. Lisonkova S, Joseph KS: Incidence of preeclampsia: risk factors and outcomes associated with early- versus late-onset disease. Am J Obstet Gynecol 2013, 209:544.

5. MacKay AP, Berg CJ, Atrash HK: Pregnancy-related mortality from preeclampsia and eclampsia. Obstet Gynecol 2001, 97:533-538.

6. Odegard RA, Vatten LJ, Nilsen ST, Salvesen KA, Austgulen R: Preeclampsia and fetal growth. Obstet Gynecol 2000, 96:950-955.

7. Maynard SE, Min JY, Merchan J, Lim KH, Li J, Mondal S, Libermann TA, Morgan JP, Sellke FW, Stillman IE, Epstein FH, Sukhatme VP, Karumanchi SA: Excess placental soluble fms-like tyrosine kinase 1 (sFlt1) may contribute to endothelial dysfunction, hypertension, and proteinuria in preeclampsia. J Clin Invest 2003, 111:649-658.

8. Levine RJ, Maynard SE, Qian C, Lim KH, England U, Yu KF, Schisterman EF, Thadhani R, Sachs BP, Epstein FH, Sibai BM, Sukhatme VP, Karumanchi SA: Circulating angiogenic factors and the risk of preeclampsia. N Engl J Med 2004, 350:672-683.

9. Reimer T, Rohrmann H, Stubert J, Pecks U, Glocker MO, Richter DU, Gerber $B$ : Angiogenic factors and acute-phase proteins in serum samples of preeclampsia and HELLP patients: a matched-pair analysis. J Matern Fetal Neonatal Med 2013, 26:263-269.

10. Verlohren S, Galindo A, Schlembach D, Zeisler H, Herraiz I, Moertl MG, Pape J, Dudenhausen JW, Denk B, Stepan H: An automated method for the determination of the SFLT-1/PIGF ratio in the assessment of preeclampsia. Am J Obstet Gynecol 2010, 202:161.

11. McElrath TF, Lim KH, Pare E, Rich-Edwards J, Pucci D, Troisi R, Parry S: Longitudina evaluation of predictive value for preeclampsia of circulating angiogenic factors through pregnancy. Am J Obstet Gynecol 2012, 207:407.

12. McElrath TF, Lim KH, Pare E, Rich-Edwards J, Pucci D, Troisi R, Parry S: The sFLT-1/PIGF ratio in different types of hypertensive pregnancy disorders and its prognostic potential in preeclamptic patients. Am J Obstet Gynecol 2012, 206:58.

13. Thadhani R, Kisner T, Hagmann H, Bossung V, Noack S, Schaarschmidt W Jank A, Kribs A, Cornely OA, Kreyssig C, Hemphill L, Rigby AC, Khedkar S, Lindner TH, Mallmann P, Stepan H, Karumanchi SA, Benzing T: Pilot study of extracorporeal removal of soluble fms-like tyrosine kinase 1 in preeclampsia. Circulation 2011, 124:940-950.

14. Cnossen JS, Morris RK, ter Riet G, Mol BW, van der Post JA, Coomarasamy A, Zwinderman AH, Robson SC, Bindels PJ, Kleijnen J, Khan KS: Use of uterine artery Doppler ultrasonography to predict pre-eclampsia and intrauterine growth restriction: a systematic review and bivariable meta-analysis. CMAJ 2008, 178:701-711. 
15. Myatt L, Clifton RG, Roberts JM, Spong CY, Hauth JC, Varner MW, Wapner RJ, Thorp JM Jr, Mercer BM, Grobman WA, Ramin SM, Carpenter MW, Samuels P, Sciscione A, Harper M, Tolosa JE, Saade G, Sorokin Y, Anderson GD: The utility of uterine artery Doppler velocimetry in prediction of preeclampsia in a low-risk population. Obstet Gynecol 2012, 120:815-822.

16. Schaffer H: Doppler-Referenzkurven. In Dopplersonographie in Geburtshilfe und Gynäkologie. Heidelberg Berlin New York: Springer Verlag; 2000:292-293.

17. Bhide A, Acharya G, Bilardo CM, Brezinka C, Cafici D, Hernandez-Andrade E, Kalache K, Kingdom J, Kiserud T, Lee W, Lees C, Leung KY, Malinger G, Mari G, Prefumo F, Sepulveda W, Trudinger B: ISUOG practice guidelines: use of Doppler ultrasonography in obstetrics. Ultrasound Obstet Gynecol 2013, 41:233-239.

18. Report of the National High Blood Pressure Education Program Working Group on High Blood Pressure in Pregnancy. Am J Obstet Gynecol 2000, 183:S1-S22.

19. von Dadelszen $P$, Magee $L A$, Roberts JM: Subclassification of preeclampsia. Hypertens Pregnancy 2003, 22:143-148.

20. Voigt M, Rochow N, Hesse V, Olbertz D, Schneider KT, Jorch G: Short communication about percentile values of body measures of newborn babies. Z Geburtshilfe Neonatol 2010, 214:24-29.

21. Schiettecatte J, Russcher H, Anckaert E, Mees M, Leeser B, Tirelli AS, Fiedler GM, Luthe H, Denk B, Smitz J: Multicenter evaluation of the first automated Elecsys sFLT-1 and PIGF assays in normal pregnancies and preeclampsia. Clin Biochem 2010, 43:768-770.

22. Ohkuchi A, Hirashima C, Suzuki H, Takahashi K, Yoshida M, Matsubara S, Suzuki M: Evaluation of a new and automated electrochemiluminescence immunoassay for plasma sFLT-1 and PIGF levels in women with preeclampsia. Hypertens Res 2010, 33:422-427.

23. Faul F, Erdfelder E, Buchner A, Lang AG: Statistical power analyses using G*Power 3.1: tests for correlation and regression analyses. Behav Res Methods 2009, 41:1149-1160.

24. Espinoza J, Kusanovic JP, Bahado-Singh R, Gervasi MT, Romero R, Lee W, Vaisbuch E, Mazaki-Tovi S, Mittal P, Gotsch F, Erez O, Gomez R, Yeo L, Hassan SS: Should bilateral uterine artery notching be used in the risk assessment for preeclampsia, small-for-gestational-age, and gestational hypertension? J Ultrasound Med 2010, 29:1103-1115.

25. Kusanovic JP, Romero R, Chaiworapongsa T, Erez O, Mittal P, Vaisbuch E, Mazaki-Tovi S, Gotsch F, Edwin SS, Gomez R, Yeo L, Conde-Agudelo A, Hassan SS: A prospective cohort study of the value of maternal plasma concentrations of angiogenic and anti-angiogenic factors in early pregnancy and midtrimester in the identification of patients destined to develop preeclampsia. J Matern Fetal Neonatal Med 2009, 22:1021-1038.

26. Velauthar L, Plana MN, Kalidindi M, Zamora J, Thilaganathan B, Illanes SE, Khan KS, Aquilina J, Thangaratinam S: Uterine artery Doppler in the first trimester as a risk factor for adverse pregnancy outcomes: A meta-analysis involving 55,974 women. Ultrasound Obstet Gynecol 2013, 43:500-507.

27. Akolekar R, Syngelaki A, Poon L, Wright D, Nicolaides KH: Competing risks model in early screening for preeclampsia by biophysical and biochemical markers. Fetal Diagn Ther 2013, 33:8-15.

28. Myers JE, Kenny LC, McCowan LM, Chan EH, Dekker GA, Poston L, Simpson NA, North RA: Angiogenic factors combined with clinical risk factors to predict preterm pre-eclampsia in nulliparous women: a predictive test accuracy study. BJOG 2013, 120:1215-1223.

29. Scazzocchio E, Figueras F, Crispi F, Meler E, Masoller N, Mula R, Gratacos E: Performance of a first-trimester screening of preeclampsia in a routine care low-risk setting. Am J Obstet Gynecol 2013, 208:203.

30. Roberge S, Giguere Y, Villa P, Nicolaides K, Vainio M, Forest JC, von Dadelszen P, Vaiman D, Tapp S, Bujold E: Early administration of low-dose aspirin for the prevention of severe and mild preeclampsia: a systematic review and meta-analysis. Am J Perinatol 2013, 29:551-556.

31. Schleussner E, Lehmann T, Kahler C, Schneider U, Schlembach D, Groten T: Impact of the nitric oxide-donor pentaerythrityl-tetranitrate on perinatal outcome in risk pregnancies: a prospective, randomized, double-blinded trial. J Perinat Med 2014, 42:507-514.

32. Becker $R$, Keller $T$, Kiesewetter $H$, Fangerau $H$, Bittner U: Individual risk assessment of adverse pregnancy outcome by multivariate regression analysis may serve as basis for drug intervention studies: retrospective analysis of $\mathbf{4 2 6}$ high-risk patients including ethical aspects. Arch Gynecol Obstet 2013, 288:41-48.
33. Belizan JM, Villar J, Gonzalez L, Campodonico L, Bergel E: Calcium supplementation to prevent hypertensive disorders of pregnancy. N Engl J Med 1991, 325:1399-1405.

34. Tidwell SC, Ho HN, Chiu WH, Torry RJ, Torry DS: Low maternal serum levels of placenta growth factor as an antecedent of clinical preeclampsia. Am J Obstet Gynecol 2001, 184:1267-1272.

35. Villa PM, Hamalainen E, Maki A, Raikkonen K, Pesonen AK, Taipale P, Kajantie $\mathrm{E}$, Laivuori $\mathrm{H}$ : Vasoactive agents for the prediction of early- and late-onset preeclampsia in a high-risk cohort. BMC Pregnancy Childbirth 2013, 13:110.

36. Krauss T, Pauer HU, Augustin HG: Prospective analysis of placenta growth factor (PIGF) concentrations in the plasma of women with normal pregnancy and pregnancies complicated by preeclampsia. Hypertens Pregnancy 2004, 23:101-111.

37. Hassan MF, Rund NM, Salama AH: An Elevated Maternal Plasma Soluble fms-Like Tyrosine Kinase-1 to Placental Growth Factor Ratio at Midtrimester Is a Useful Predictor for Preeclampsia. Obstet Gynecol Int 2013, 2013:202346.

38. Unal ER, Robinson CJ, Johnson DD, Chang EY: Second-trimester angiogenic factors as biomarkers for future-onset preeclampsia. Am J Obstet Gynecol 2007, 197:211-214.

39. Tjoa ML, van Vugt JM, Mulders MA, Schutgens RB, Oudejans CB, van Wijk IJ: Plasma placenta growth factor levels in midtrimester pregnancies. Obstet Gynecol 2001, 98:600-607.

40. Vatten LJ, Eskild A, Nilsen TI, Jeansson S, Jenum PA, Staff AC: Changes in circulating level of angiogenic factors from the first to second trimester as predictors of preeclampsia. Am J Obstet Gynecol 2007, 196:239-6.

41. Romero R, Nien JK, Espinoza J, Todem D, Fu W, Chung H, Kusanovic JP, Gotsch F, Erez O, Mazaki-Tovi S, Gomez R, Edwin S, Chaiworapongsa T, Levine RJ, Karumanchi SA: A longitudinal study of angiogenic (placental growth factor) and anti-angiogenic (soluble endoglin and soluble vascular endothelial growth factor receptor-1) factors in normal pregnancy and patients destined to develop preeclampsia and deliver a small for gestational age neonate. J Matern Fetal Neonatal Med 2008, 21:9-23.

42. Stepan H, Unversucht A, Wessel N, Faber R: Predictive value of maternal angiogenic factors in second trimester pregnancies with abnormal uterine perfusion. Hypertension 2007, 49:818-824.

43. Moore Simas TA, Crawford SL, Solitro MJ, Frost SC, Meyer BA, Maynard SE: Angiogenic factors for the prediction of preeclampsia in high-risk women. Am J Obstet Gynecol 2007, 197:244-248.

44. Rana S, Powe CE, Salahuddin S, Verlohren S, Perschel FH, Levine RJ, Lim KH, Wenger JB, Thadhani R, Karumanchi SA: Angiogenic factors and the risk of adverse outcomes in women with suspected preeclampsia. Circulation 2012, 125:911-919.

doi:10.1186/1471-2393-14-292

Cite this article as: Stubert et al:: Prediction of preeclampsia and induced delivery at $<34$ weeks gestation by sFLT- 1 and PIGF in patients with abnormal midtrimester uterine Doppler velocimetry: a prospective cohort analysis. BMC Pregnancy and Childbirth 2014 14:292.

\section{Submit your next manuscript to BioMed Central and take full advantage of:}

- Convenient online submission

- Thorough peer review

- No space constraints or color figure charges

- Immediate publication on acceptance

- Inclusion in PubMed, CAS, Scopus and Google Scholar

- Research which is freely available for redistribution 